\title{
Дискуссии
}

Discussions

\section{Gala Maksudova-Eliseeva}

\section{Logical aliens and where to find them}

\author{
Gala Maksudova-Eliseeva \\ National Research University Higher School of Economics, \\ 20 Myasnitskaya St., Moscow, 101000, Russian Federation. \\ E-mail: maks.gala22@gmail.com
}

\begin{abstract}
This paper is concerned with Frege's logical aliens argument against psychologism in logic that leans on the ideas of uniqueness of logic and the understanding of normativity of logic in such a way that everybody should obey the rules of the classical logic system in all circumstances. The paper argues that this argument becomes too radical in the context of current philosophy in logic. The possible answer to Frege's argument could be inspirited by the philosophical ideas of later Wittgenstein: we play different language games, and some of them are logical games. Logical reasoning is to be understood as a kind of dialogical practice and in the process of the ontogeny people learn some sorts of logical games typical for their culture and concerned with their activity. However, different people have different criteria of certainty and not all of them can play logical games. The capacity to play logical games depends on various factors (e.g. culture, educational level, motivation, etc.) and it is connected with main practices that one involved in. In order to talk about logical aliens one should first find out what criteria of certainty his opponent has and what language game he or she plays. This gives new comprehension of the normativity of logic that shows that there are no logical aliens in absolute sense. This view can give in turn a new understanding of what rationality is and show why logic and psychology should interact.
\end{abstract}

Keywords: Frege, logical aliens, logical pluralism, logical reasoning, normativity of logic, psychologism

For citation: Maksudova-Eliseeva G. "Logical aliens and where to find them", Logicheskie Issledovaniya / Logical Investigations, 2020, Vol. 26, No. 2, pp. 160-175. DOI: 10.21146/20741472-2020-26-2-160-175

\section{Introduction}

The aim of this paper is to reconsider the logical aliens argument. The term "logical aliens" was coined by James Conant Conant, 1991], while the argument originates in the Introduction to Frege's book "Grundgesetze der Arithmetik" Frege, 1893 where Frege argues against psychologism and its understanding of what kind of thing the law of logic is. He suggests that we should imagine that 
if men or other beings were discovered who could reason successfully basing on the other laws of logic. For Frege it is impossible, and therefore is to be considered as a "hitherto unknown type of madness" [Frege, 1964, XVI]. This argument is a part of Frege's whole conception of logic, which is essentially antipsychologistical. The triumph of antipsychologism as a result of the controversy over psychologism in logic on the cusp of the 19th and 20th centuries formed a language of the philosophy of logic and its basic distinctions for a significant period. However, a growing number of recent researches suggest some new categories in which logic could be understood. This gives an opportunity to catch the logical aliens. Therefore, in order to investigate who logical aliens are, one should first find out how logic relates to human reasoning. In that regard, the normativity of logic is of our greatest interest. In the first section, I want to present the logical aliens argument. Then I will outline some current ideas in philosophy of logic. The third section will be a step back to logical aliens in order to establish that the possibility of logical aliens' existence includes non-logical dimensions.

Still, why do we need to make efforts to find out who logical aliens are? This problem looks like another variation of the philosophical problem of the Other. It is formulated with respect to the defined professional group, whether that be philosophers, logicians, psychologists, etc. There are a lot of possible characteristics of division. And there a pertinent question arises, whether we really need another one, based on the specific character of the logical reasoning. Within this context, three kinds of risk are possible. First, there is a danger to divide people straightforwardly and uncompromisingly into two categories: people who reason like me/we/all of us/the majority and the Others. It looks like a logical orientalism. From historical perspective it became a problem in the days of the construction of the first intelligence tests. The second kind of risk is to ignore the consistent profiles of the reasoning in favour of globalism. The third one is relativism, so that logic loses the connection with rationality and cannot be appointed as "arbiter in the conflict of opinions" [Ibid., XIX]. How is it possible to avoid these traps?

\section{Logical aliens argument}

Some of Frege's ideas concerning philosophy of logic will be our starting point in our search. Since Frege attempts to underpin arithmetic by using logical axioms, he first has to provide some evidence that logic has an independent existence from the mind. In the introduction to "Grundgesetze der Arithmetik" he gets into an argument with psychologists regarding the question of the origin of the logical laws. First of all, the laws of logic and the psychological laws should not be confused, otherwise it leads to the breaking of 
the distinction between the objective and subjective. The laws of logic are the laws of truth itself, while psychological ones only concern "taken to be true". For this reason, it is impossible to discover the former kind of laws by describing someone's thoughts. Controversially, logic appears as an absolute point of view and, therefore, takes on the role of the court, which points out whose reasoning is correct. In this sense, logic is descriptive (it describes the laws of truth) and normative for thought. Its laws are "the most general laws, which prescribe universally the way in which one ought to think if one is to think at all" Frege, 1964, XV]. Only in this sense, they can have a special title "laws of thought".

Nevertheless, there are no creatures "whose laws of thought flatly contradicted ours and therefore frequently led to contrary results even in practice" [Ibid., XVI]. For Frege, here it would be a kind of madness, that, however, nobody saw, whereas in contrast the psychological logician could only say: "those laws hold for them, these laws hold for us" [Ibid., XV]. Frege concedes that there could be some beings governed by induction rather than deduction, but they obtain the same result using other proceeds. Thus, Frege postulates the one world, and logic correctness remains the unique criterion for reasoning correctness. In other words, the laws of logic are constitutive for rationality. However, there remain two main questions. The first one inherited from Plato: if these laws are ideal and we cannot furthermore see or touch them, how can we conceive them? We cannot perceive these laws in order to characterise them. We cannot use consistency of the system as well, because there can be more than one unique consistent system. We have to refer to some of our intuitions or experience or to establish in a formalised manner what to start with. The last decision pertains to David Hilbert, and Frege strongly disagreed with this approach. The second is, even though it is possible to discover logical laws, it should be first justified why we should follow them.

Frege's conception of logic is directly related to the basic notions and distinctions of his time. The uniqueness of logic was a common point for all researchers involved in this argument, and logicians should find foundation for this logic. The controversy was about three main issues: constitutiveness of logic, descriptiveness, and normativity. The first issue is, whether this unique logic is constitutive for our reason, that is, if we really cannot help but think in accordance with its rules. The second is concerned with the possibility of logic as empirical science, which had its substance in the psychology of thought. The third issue is about normativity. The statement that logic is normative for reasoning is widespread. This was a common point for some psychologism supporters (e.g., Wilhelm Wundt) and antipsychologists, so it would be inaccurate to say, that there is an opposition between logic as descriptive (psychologists) and normative, or prescriptive (antipsychologists) science. If there is only one 
correct system and it is normative, one should inviolately follow its rules under any circumstances in order to stay rational. Then logic becomes a Procrustean bed for human reasoning. On the other hand, it is inappropriate to deny the laws of logic as irrelevant to human reasoning or to relativise rationality towards different kinds of societies.

\section{Challenging Frege}

There is a plethora of problems related to the controversy over psychologism. Some of them receded into historical distance, for example, by now nobody holds a view that logic is a descriptive science with its grounds in the empirical psychology of thought. The idea of constitutiveness of logic is not widespread as well. Some of the questions appear in a new light, while some hold their sway. However, the Frege's argument is challenged due to the ideas that will be presented below.

\subsection{Constitutiveness of logic}

The idea of constitutiveness was more typical for psychologists, because they undertook attempts to derive logic from real thoughts. However, not only they advocate this idea. At least Kant and early Frege were of the same belief. Frege forewent this thesis only in "Grundgesetze der Arithmetik" Linnebo, 2003. For example, Robert Hanna tries to defend the "broadly Kantian theory of human rationality", namely, that there is a protologic constitutive for human cognition. All the logical systems are developed on the base of this protologic. However, "protologic itself is neither a classical or elementary logic, nor a nonclassical logic, nor strictly speaking even a logical system as such, but is instead an all-purpose logical tool-kit used for cognitively constructing, analyzing, and comparatively evaluating logical systems" [Hanna, 2006, p. 133]. We are hardly capable to say something about such protologic. In any case, if it even exists, it does not lead to the innateness of logic. Logical form is not something preset and "revealing of the logical form is an inventive, design, engineering activity that uses a limited set of tools and is focused on specific goals" DragalinaChernaya, 2015, p. 126], therefore, we are responsible for this process. Logic is neither an inborn component of our reason, nor a kind of necessarily developing (in Piaget-style) competence.

Participants of the controversy over psychologism dissented on what the boundary of logic is. It was more typical for psychologistic thinkers to base their theories upon traditional logic, while the antipsychologistic view is inextricably connected with the origin of symbolic logic. Nevertheless, both groups could not even imagine the possibility of alternative logic systems. The controversy over logical pluralism became possible after the first alternative logic systems 
had been offered. The main claim of logical monists ${ }^{1}$ is that there is only one correct logic. On the other hand, logical pluralists underline the idea that there is more than one correct $\operatorname{logic}^{2}$. Nevertheless, no matter what belief one holds, the notion of the uniqueness of logic has been challenged.

\subsection{Normativity of logic}

The issue of the normativity of logic remains dominant. A significant number of articles are published annually with the focus on this question. Several authors have abandoned this idea completely Eukasiewicz, 1957; Zaytsev, 2018: Shramko, 2014; Shramko, 2018], because logic appears to be a science concerned with ontology and has nothing to do with reasoning. This approach is a part of the realistic view on logic, that is, "the fundamental principles of one logic or another turn out to be just specific ontological preconditions imposed on the given logical world" [Shramko, 2014, p. 126]. On the other hand, Van Benthem writes: "And I think the following should be obvious: if logical theory were totally disjoint from actual reasoning, it would be no use at all, for whatever purpose!" van Benthem, 2008, p. 69]. Moreover, let us imagine a logician who does not follow identity law (here we refrain from the discussion about the question, what it means to follow the logical laws). We would be startled by such a meeting. Possibly, we would even exclaim, that this is "a hitherto unknown type of madness!"

Of course, there are some difficulties with the normativity thesis. Only the most important will be presented below. Firstly, a sufficient amount of experiments (e.g., the classical ones undertaken by Wason, 1966 and Byrne, 1989|) ${ }^{3}$ have shown that not only did the people with mental disorders or uneducated people commit logical fallacies systematically, but also educated western people did. Nevertheless, it does not look like they all are not rational at all. "If the rules of inference are considered to be an a priori condition of the possibility of rationality as such, people who statistically violate these rules should be deemed as irrational. However, how can non-rational beings act adaptively, survive and even evolve?" Dragalina-Chernaya, 2015, p. 126]. Secondly, logicians can formalise, or develop a logical model of the particular aspects of different subjects' reasoning. For example, Stenning and Lambalgen have modeled some patterns of reasoning of autistic people and children with ADHD (attention deficit hyperactivity disorder) [Stenning, van Lambalgen, 2007]. If these patterns are persistent, can be formalised and sometimes lead us to new unusual

\footnotetext{
${ }^{1}$ See, e.g., Read, 2006 .

${ }^{2}$ See, e.g., Shapiro, 2014.

${ }^{3}$ Some details concerning cross-cultural studies will be discussed in the next section.
} 
practical results ${ }^{4}$, where is a clear dividing line between such models and other logical systems? Should we regard such models as normative? Thirdly, there are many logical systems, which have a different conception of what logical consequence is. This is a big question of whether we are able to prefer one system to another. If yes, how do we choose the correct one? If there is no core, or canonical application of logic, we should assign the incommensurability of the different forms of reasoning. Nevertheless, even if we want to find only one system, which is correct and normative in an absolute sense, we get caught in a vicious circle. Justifying the normativity of logic towards reasoning, we postulate an ideal reasoning subject, but the normativity of such a subject's reasoning is due to the fact that he is guided by logical norms MacFarlane, 2004 Dragalina-Chernaya, 2015. Fourthly, deductive reasoning warrants too many resources, so in some situations it is not rational to inference taking into account all possible models. There are some situations when it is not rational to perform deductive inference.

Stenning and Lambalgen offer to abandon the idea of the normativity of logic in a traditional sense, namely, that everybody should obey the rules of the classical logic system in all circumstances. Their claim is that absolute distinction between valid and invalid arguments cannot been found. Our reasoning is domain dependent and the valid schemata is governed by the domain in which one reasons and by an individual's purpose. Therefore, reasoning can be viewed as consisting of two levels. On the first level one establishes the domain of reasoning and its formal properties ("reasoning to an interpretation"), and only after this within this domain one starts to use formal laws and is guided by them ("reasoning from an interpretation"). The first part is informal, while on the second level we can consider the normativity of logic in a familiar sense. So that we can speak about logical fallacies in frames of every system Stenning, van Lambalgen, 2008. Vladimir Vasyukov accounts as well that in the era of non-classical science the choosing of a logical system involves also a non-logical dimension, and "scientific pluralism should also be perceived as a consequence of the variability of the system of social values and goals, dictating the choice of various research strategies" [Vasyukov, 2015, p. 82].

It is one of the possible approaches to the normativity of logic. As one can see, Stenning and Lambalgen try to maintain the idea of normativity, and they are constrained to take into account an informal reasoning: in order to understand if someone follows the logical laws, we should first establish how one has interpreted the task.

\footnotetext{
${ }^{4}$ For example, some big companies have started adjusting working areas for autistic people Patterson, 2018.
} 


\subsection{Logic and culture}

Frege (whose starting point was logical theory) argued the normative status of logic for all people, including people from other cultures: if one does not think logically, one does not think at all. Anthropologists (who observe people of other cultures) noticed that people could think successfully violating basic logical laws, and sociologist David Bloor relativised logic towards social institutes. Bloor analysed some reasoning patterns of the Azande people when they were asked about some aspects of magic, which was a significant part of their lives. The Azande took as true two beliefs in contradiction and did not change them after researchers highlighted the contradiction. Bloor concluded, that there were a lot of forms of logics, for instance, logic of the Azande, western logic etc. and noted: "The Azande have the same psychology as us but radically different institutions. If we relate logic to the psychology of reasoning we shall be inclined to say that they have the same logic; if we relate logic more closely to the institutional framework of thought then we shall incline to the view the two cultures have the different logics" [Bloor, 1976, pp. 129-130].

Nevertheless, it is not difficult to cognise, that the Azande do not have logic as a theory of formal systems, they have some patterns in their reasoning. What Bloor is talking about is not logic. May be the Azande do not think at all, as Frege believed? However, they are successful in their practices and logical analysis of their beliefs can even destroy their practice. Six years earlier in 19311932 the soviet psychologist Alexander Luria undertook a seemingly similar study with undereducated people that lived in kishlaks of Uzbekistan. However, he distinguished between logic and the process of reasoning, and he proceeded from the thesis of the uniqueness of logic. Luria gave to participants various tasks and observed how different groups deviate from the logical solution. He showed that the ways of reasoning and problem solving were dependent on the forms of the activity typical for every society: farmers without any education were unable to solve syllogisms, while farmers of elementary education were capable to solve syllogisms with premises based on their actual experience. And none of them could infer from the premises that were not connected with their practice. Luria, 1976]. So, this research counts in favour of the culturally based disposition of logical reasoning. Catarina Dutilh Novaes follows this idea and points out, that we can expect reasoning in accordance with logical laws only if a subject has studied logic. Logic could be named normative science only in a few situations of the explicit dispute Dutilh Novaes, 2013; Dutilh Novaes, 2015. 


\section{Back to logical aliens}

At the present some researches are going to change some basic points of the antipsychologistic philosophy of logic, even bringing in some psychological details to Frege's conception [Bryushinkin, 1998]. The former philosophy of logic lets us only deny the possibility of logical aliens (or in an extreme view, we cannot even meaningfully think of such a possibility Conant, 1991|) or encounter beings who think in brand new ways. The new perspective gives us an ability to understand that logical aliens are not an absolute category, and they can be among us.

The possible decision that helps to avoid both relativism and Frege's dogmatism is to conceive human activity not excepting reasoning as consisting of different language games ${ }^{5}$ in Wittgenstein-style. These games serve the purposes of the subjects of the particular culture, and people learn such games in the process of ontogeny. Different games concern with a different understanding of what is rational. Language games, as a form of life, incorporate a practical component, so there can be games within spiritual practices (where contradiction does not constitute a problem, and a man can be a turtle at the same time $\left.{ }^{6}\right)^{7}$, within household practices, etc. There is also a subset of logical games. The main characteristic of logical games is a competence to separate form from content and consequently ability to inference in isolation from experience. This subset is not homogeneous. We should distinguish between logical games in the narrow sense and in the broad sense. Gilbert Harman points out that "it is crucial not to confuse issues of implication with issues of inference" that are "very different things" Harman, 2002, p. 1]. Logic is a theory of implication as a direct relation between propositions that uses formal systems as its method, whereas the theory of inference, where inference is understood as a psychological process leading to possible changes in belief or intentions. Logical games in the narrow sense are something only logicians can play. Christian Greiffenhagen and Wes Sharrock notice "even if formal logic has been developed in one

\footnotetext{
${ }^{5}$ Only situations where a subject expresses the process of one's solution in language and does not limit oneself to silently pointing to the correct answer will be considered.

6 Frazer, 2005.

${ }^{7}$ Emile Durkheim notices that following logical laws differs in every society: "Today the principle of identity governs scientific thought; but there are vast systems of representation [...], in which it is commonly ignored. These systems are the mythologies [...]. Mythologies deal with beings that have the most contradictory attributes at the same time, that are one and many, material and spiritual, and capable of subdividing themselves indefinitely without losing that which makes them what they are" Durkheim, 1995, p. 12]. However, for Durkheim these illogical forms remain in the past. Nevertheless, we can find such a kind of out-of-logic practices in modern society, for example, in religion. One person can be very logical while working with scientific concepts and uses concepts that contain contradictive characteristics while reasoning about God.
} 
culture, it is not really the whole culture which has done so. Rather, formal logic has typically been developed as part of some highly specialized practices" Greiffenhagen, Sharrock, 2006, p. 280]. This kind of games are connected with very special practices of developing and studying logical systems. The diversity of logical systems is not ontologically rooted in the human minds and in the ways of how human beings reason or solve tasks. However, the practice of logical systems' developing helps to acquire competencies in playing logical language games.

Logical games in a broad sense concern the presence of the question of rational justification and with the understanding that logical correctness is an important part of reasoning. However, it does not mean that people who can play such games can consciously reflect on the rules of logic. Paul Boghossian poses a problem of blind reasoning: how is "blind but blameless inference a way of moving between thoughts that is justified even in the absence of any reflectively appreciable support for it" possible? [Boghossian, 2003, p. 248]. Boghossian examines the problem addressing inferences of the modus ponens (MP) form as an example and concludes that MP is a precondition for possession of the concept of "conditional". However, we obtain this kind of inference from practice (otherwise how could MP be a "precondition" providing that we do not have notice of it?), that is, our parents say something to us in the form "if ..., then ...", our teachers show us how to use calendars and timetables, they also direct our attention to regularities, etc. Indeed, we do not commit logical fallacies in familiar, everyday situations (for instance, "if today is the 20th, then Martha Argerich is playing today in Carnegie Hall. Today is 20th. Then ..." Boghossian, 2003, p. 225]) Moreover, we do not even conceive this situation as a logical one. Nevertheless, as mentioned above, people from our culture commit logical mistakes systematically when solving some kind of tasks that demand logical reasoning. If the task content is connected with the practice or an important domain, people cope with it far better ${ }^{8}$. However, western people demonstrate a modicum of logical competence when solving abstract tasks as well. They have some intuitions about logical correctness, which can be reflected in a greater or lesser degree. This is because they have been involved in particular dialogical practices during their education. For example, schooling forms that include such a kind of dialogical interaction where a teacher formulates claims that other participants accept as true statements and try to reason thereupon. [Dutilh Novaes, 2015]. So, by the logical games in a broad sense, we mean such a kind of games where rational agents have an idea of logical correctness, and they are capable of recognising the situations that demand logical thinking. This group of games is heterogeneous as

\footnotetext{
${ }^{8}$ See, e.g. Fiddick et al., 2000.
} 
well, for example, scientific challenges require maximum accurate consideration with explication of all premises, exceptions and threads of argumentation, while practical reasoning by no means always demand such accuracy. It does not mean that people do not need logic in everyday life - in fact, they do need it. However, deduction demands too much timing, computational and storage budgets, so that, in ordinary cases, it is rational to fast track a decision rather than make a deductive inference.

However, not all cultures play logical games, because they are not familiar with this practice and cannot even understand what the researcher expects. "These examples [of performing the tasks] show that syllogisms are not perceived by these subjects as unified logical systems. The subjects repeat different parts of the syllogisms as isolated, logically unrelated phrases" Luria, 1976, p. 106]. Finally, "the subjects refused to resort to logical inference from the given premises" [Ibid., p. 108]. It does not exclude that they have some forms of "epistemically blameless blind reasoning" (from a logical point of view), when the task concerns their practice, but it does not mean that they are using laws of classical logic. They also can give a correct answer for syllogism or manage with a task like "The meal in the round dish is poisoned" and refuse this dish, however, the explanation will be non-logical. People from these cultures have an idea of reasoning correctness, the correctness of changing in belief as well, yet it is concerned with another understanding of the possible ways of their judgements' justification: it is not a rational, logical justification. For instance, uneducated Uzbeks appealed to experience while dealing with syllogism: "we've never been anywhere, so we don't know" [Ibid., p. 106]. As a result of the elimination of illiteracy, these subjects get acquainted with logical games and learn the skill to separate the form from content.

Nevertheless, it does not mean that logical relativism is to be supported. It leads to an opposite view: there are no logical aliens at all (because all people have their own style in reasoning) or that every human can be called a logical alien by any other human (for the same reason). Something that could be named "relative relativism" or a weak version of logical constructivism looks more appropriate [Dutilh Novaes, 2013], that is, there are rules of deductive logic that establish rules for ideal situations and real reasoning in different situations. Furthermore, different logical systems ${ }^{9}$ can be normative as described above - in some particular situations, for some kinds of language games. I suppose, that the apprehension of somebody as a logical alien concerns not only logical dimension but also social and psychological ones. In which situations is it relevant to speak about logical aliens? It depends on two interrelated factors:

\footnotetext{
${ }^{9}$ See Stenning and Lambalgen's idea on two levels of reasoning.
} 
1. The components of a subject's certainty. 2. A subject's expectations within a particular language game.

Subjects involved in different practices have different criteria of certainty Wittgenstein, 1970]. Following Wittgenstein, certainty is one's set of basic beliefs about the world, which one rests upon in his practice or thinking without bringing these beliefs into question. That's why doubt about them is nonproductive and meaningless, consequently making a person "a madman". For a logician, who can play logical games in the narrow sense, logical laws themselves grow into one's certainty. It means that they do not need too many resources to solve a logical puzzle (like the Wason-test), they have an inner weapon for such puzzles and can extend logical thinking to a broader set of situations. Of course, this does not mean that all logical games they can play (for example, with material implication) pertain to their basic beliefs. However, they acquire a form of life that includes the possibility to play logical games. The question is, whether logicians doubt the logical laws. May-be they do, but some particular laws, not logic as such. For example, relevant logic started as an attempt to avoid some counter-intuitive paradoxes of material implication. Though, this doubt is possible only within logic. Students, after a basic course of logic, make little less mistakes than they did before the class (according to my own observation). It can be interpreted in such a way that for such students, the laws of logic did not become a part of the thought practice, whereas professors of logic hardly ever make a mistake in this task. Students have an idea of logical correctness, but logical canons are not reflected by them. For instance, van Benthem writes about a psychologist mentioning that he had never met an experimental subject who did not understand the logical solution of the Wason-task when it was explained to him van Benthem, 2008.

Therefore, a rough distinguishing could be made between people with logical education and people without it. No logician (after the Wason-task) expects an uneducated person to reason in absolute accordance with the formal rules, but so called ordinary people may anticipate that logicians reason like an ideal reasoner mentioned above (presumably ${ }^{10}$ ordinary people, if we ask them, would answer that logical laws are normative for reasoning and appear to be supporters of the naive psychologism). Another distinguishing factor is between people without any education and people with some logical competence. This contrasts with Wittgenstein's idea. People from different cultures or even inside one culture may have different criteria of certainty.

\footnotetext{
${ }^{10}$ Bryushinkin mentions "interpretation of the laws of logic and logical forms as forms and laws of thought is in their eyes the single justification for the complex set of logical studies. We can say that the "man from the street' is always a 'naive psychologist" Bryushinkin, 1998 .
} 
It is crucial to find out whether our opponent plays the same game (and understand at large what kind of game it is). One may not know this game or can prefer not to play a logical game and take a risk to use another tool. Susan Haack writes: "Logic, I suggested, is prescriptive of reasoning in the limited sense that inference in accordance with logical principles is safe. (Of course, safety needn't be an overriding consideration; one might, quite rationally, prefer fruitful but risky to safe but relatively uninteresting procedures...)" (Haack, 1978 , p. 241]. If a proponent is not familiar with such a kind of games (like the Azande) or has different practical interests (and one's reasoning is successful in the frames of one's basic interests), this person can be named neither a logical alien nor a logical relative.

Concerning this problem, it is more interesting to examine the thought of people with the modicum of logical competence including logicians. People expect that their opponents have the same criteria of certainty, while playing particular language game. There are two possible examples of situations where it is possible to speak about logical aliens:

1. Two logical monists discuss one particular case. At one moment one of them conceives that one's opponent adheres to another system of implication (for example, relevant logic), while the proponent uses the classic system. In the frames of this particular game both of them could consider each other as logical aliens.

2. A teacher of logic says to students that a falsehood implies any proposition. This is a real surprise for students. Logic is illogical, we do not think in this way! ${ }^{11}$

There are also some other kinds of activities that include logical language games as their components: particular tasks in the employment interview, diagnosis of cognitive functions within the psychiatric clinic ${ }^{12}$, homework preparation, etc. Considering this, we can point out the following dimensions in searching for logical aliens:

1. Cultural: one should comprehend that his or her opponent has the same criteria of basic certainty. A lot of questions remain within cross-cultural studies regarding the boundaries of rationality in different cultures. However, we can expect some unfamiliar patterns in reasoning. These patterns can lead to success in some special tasks' solutions that are connected with practices.

\footnotetext{
${ }^{11}$ Only a few students during the course can cognise this issue. I suppose, it confirms the idea that student do not engage logical principles as a part of their practice.

${ }^{12}$ See, e.g. Vygotsky, 1956 .
} 
2. Logical: it is crucial to make sure that one's opponent is at least familiar with some kinds of logical games, that is, one can separate form from content.

3. Psychological: one should have some expectations about the current logical game. Participants should have a shared sense of purpose. Sometimes our colleagues turn out to be more aliens than people of other cultures. Thus, somebody could be called "a logical alien" if one is situated within a particular language game. This foreignness is not absolute, and a person can be good in some kinds of games, and bad in other ones.

\section{Summary}

The logical aliens' argument was very important for antipsychologism. However, some current ideas of philosophy of logic offer the possibility to review the categoricity of Frege's approach. Frege's conception of logical aliens correlates with the particular view on what logic is and how it can be normative. In spite of the fact that relations between logic and real reasoning are still not obvious and remain under the process of revision by philosophers and psychologists, the philosophy of logic as well as logic itself, has achieved significant progress. Nevertheless, with this progress came new problems, new kinds of dispute. Current philosophy of logic has some new basic oppositions: the debating on logical pluralism and logical monism displaces the issue whether logic is constitutive for our reason, the idea of logic as description of psychological processes is substituted by the possibility of modelling the reasoning patterns. Moreover, the philosophers of logic conceived, that there is a multiplicity of circumstances where we have to reason, and every situation is governed by its own purpose. These changes encourage us to review the logical normativity problem.

In order to catch the logical aliens, we should take into account not only logical factors, but also cultural, social and psychological ones, because the rationality could not be reduced to logical thinking. Logic is not more a Procrustean bed for human reasoning, but still remains the factor of correctness. Logic does not need to be relativised against culture and has something to do with truth. Every language game, whether it be logical or shamanistic, has its own experts. However, people who have greater logical competence when they find derailments from the rules in other people's reasoning, assess the rationality in terms of logical games and in terms of logical correctness, but it is not a criteria of what is rational for practices of other cultures. So, it becomes possible to speak about different logical games and to consider the problem of logical aliens' existence concerning different situations, so that we can assess the particularities of reasoning without tagging people. We must remember, 
that first of all we all are people, and only then do we have different patterns in reasoning.

Acknowledgements. The article was prepared within the framework of the HSE University Basic Research Program.

\section{References}

Bloor, 1976 - Bloor, D. Knowledge and Social Imagery. London: Routledge, 1976. $156 \mathrm{pp}$.

Boghossian, 2003 - Boghossian, P. "Blind reasoning". Proceedings of the Aristotelian Society, 2003, Supplementary Volume, No. 77, pp. 225-248.

Bryushinkin, 1988 - Bryushinkin, V.N. Logika, myshlenie, informatsiya [Logic, thinking, information]. Saint Petersburg: Izdatelstvo Leningradskogo universiteta, 1988. 152 pp. (In Russian)

Bryushinkin, 1998 - Bryushinkin, V.N. "Psikhologizm na poroge XXI veka" [Psychologism around the turn of the millennium], in: Logicheskoe kantovedenie-4: Trudy mezhdunarodnogo seminara [Logical Kant studies: Materials of the international workshop]. Kaliningrad: Kaliningr. un-t., 1998. pp. 84-99. (In Russian)

Byrne, 1989 - Byrne, R. "Suppressing valid inferences with conditionals", Cognition, 1989, Vol. 31, pp. 61-83.

Conant, 1991 - Conant, J. "In Search of Logical Alien Thought - Descartes, Kant, Frege and the Tractatus", Philosophical Topics, 1991, Vol. 20, No. 1, pp. 115-180.

Dragalina-Chernaya, 2015 - Dragalina-Chernaya, E.G. Neformal'nye zametki o logicheskoi forme [Nonformal notes on the logical form]. Saint Petersburg: Aletheia, 2015. 202 pp. (In Russian)

Durkheim, 1995 - Durkheim, E. Elementary Forms Of The Religious Life. New York: Free Press, 1995. 464 pp.

Dutilh Novaes, 2013 - Dutilh Novaes, C. "A Dialogical Account of Deductive Reasoning as a Case Study for how Culture Shapes Cognition", Journal of Cognition and Culture, 2013, Vol. 13, pp. 459-482.

Dutilh Novaes, 2015 - Dutilh Novaes, C. "A Dialogical, multi-agent account of the normativity of logic", Dialectica, 2015, Vol. 69, No. 4, pp. 587-609.

Fiddick et al., 2000 - Fiddick, L., Cosmides, L. and Tooby, J. "No interpretation without representation: the role of domain-specific representations and inferences in the Wason selection task", Cognition, 2000, Vol. 77, pp. 1-79.

Frege, 1893 - Frege, G. Grundgesetze der Arithmetik. Bd. 1. Begriffsschriftlich abgeleitet. Jena: Verlag Hermann Pohle, 1893. XXXII +254 pp.

Frege, 1964 - Frege, G. Basic laws of arithmetic. Berkeley and Los Angeles: University of California Press, 1964. LXIII+144 pp.

Frazer, 2005 - Frazer, J.G. The Golden Bough: a study of magic and religion. New York: Cosimo Classics, 2005. XIV +718 pp. 
Greiffenhagen, Sharrock, 2006 - Greiffenhagen, C., Sharrock, W. "Logical relativism: logic, grammar, and arithmetic in cultural comparison", Configurations, 2006, Vol. 14, No. 3, pp. 275-301.

Haack, 1978 - Haack, S. Philosophy of logics. Cambridge: Cambridge University Press, 1978. 276 pp.

Hanna, 2006 - Hanna, R. Rationality and logic. Cambridge, MA: The MIT Press, 2006. 316 pp.

Harman, 2002 - Harman, G. "Internal Critique: A Logic is not a Theory of Reasoning and a Theory of Reasoning is not a Logic", in: Handbook of the Logic of Argument and Inference: The Turn Towards the Practical, ed. by D.M. Gabbay et al. Amsterdam: Elsevier Science B.V., 2002. pp. 171-186

Łukasiewicz, 1957 - Lukasiewicz, J. Aristotle's Syllogistic From the Standpoint of Modern Formal Logic. Oxford: At the clarendon press, 1957. XIV+222 pp.

Linnebo, 2003 - Linnebo, O. "Frege's conception of logic: from Kant to Grundgesetze", Manuscrito, 2003, Vol. 26, No. 2, pp. 235-252.

Luria, 1976 - Luria, A.R. The Cognitive Development: Its Cultural and Social Foundations. Cambridge: Harvard University Press, 1976. XVI +176 pp.

MacFarlane, 2004 - MacFarlane, J. "In what sense (if any) is logic normative for thought?", unpublished manuscript, 2004.

Patterson, 2018 - Patterson, G. "Fighting cybercrime with neurodiversity". Project Syndicate. 2018. https://www.project-syndicate.org/commentary/ neuro-diversity-cybersecurity-autism-asperger-by-gavin-patterson-2018-01. accessed on 13.01.2020]

Read, 2006 - Read, S. "Monism: The one true logic", in: A Logical Approach to Philosophy: Essays in honour of Graham Solomon, ed. by D. DeVidi, T. Kenyon. Berlin: Springer, 2006. pp. 193-209.

Shapiro, 2014 - Shapiro, S. Varieties of Logic. Oxford: Oxford University Press, 2014. IX +226 pp.

Shramko, 2014 - Shramko, Ya.V. "The logical way of being true: Truth values and the ontological foundation of logic", Logic and Logical Philosophy, 2014, Vol. 23. pp. 119-131.

Shramko, 2018 - Shramko, Ya.V. "Logicheskii sposob bytiya istiny" [Logical way of truth being], in: Sovremennaya logika: osnovaniya, predmet i perspektivyi razvitiya [Contemporary logic: foundations, subject, and perspectives of development], ed. D. Zaitsev. Moscow: Forum, 2018, pp. 96-110. (In Russian)

Stenning, van Lambalgen, 2007 - Stenning, K., van Lambalgen, M. "Logic in the study of psychiatric disorders: Executive function and rule-following", Topoi, 2007, Vol. 26, pp. 97-114.

Stenning, van Lambalgen, 2008 - Stenning, K., van Lambalgen, M. Human reasoning and cognitive science. Cambridge, MA: MIT University Press, 2008. XVI +407 pp.

van Benthem, 2008 - van Benthem, J. "Logic and reasoning: do facts matter?", Studia Logica, 2008, Vol. 88, No. 1, pp. 61-84. 
Vasyukov, 2015 - Vasyukov, V.L. "Gorizonty nauchnogo plyuralizma" [Horizons of scientific pluralism], Filosofiya, metodologiya i istoriya nauki [Philosophy, methodology and history of science], 2015, Vol. 1, No. 1, pp. 68-85. (In Russian)

Vygotsky, 1956 - Vygotsky, L.S. "Narushenie ponyatiy pri shizofrenii" [Thought in schizophrenia], in: L.S. Vygotsky, Izbrannyie psihologicheskie issledovaniya [L.S. Vygotsky, Selected psychological research]. Moscow: izdatelstvo akademii pedagogicheskih nauk RSFSR, 1956. pp. 481-496. (In Russian)

Wason, 1966 - Wason, P. "Reasoning about a rule", Quarterly Journal of Experimental Psychology, 1966, Vol. 20, pp. 273-281.

Wittgenstein, 1970 - Wittgenstein, L. Über Gewißheit. Frankfurt: Suhrkamp Verlag, 1970. 179 pp.

Wittgenstein, 1999 - Wittgenstein, L. Philosophical investigations / Philosophische Untersuchungen. Oxford: Basil Blackwel, 1999. 272 pp.

Zaytsev, 2018 - Zaytsev, D.V. "Logika, rassuzhdeniya, informatsiya" [Logic, reasonings, information], in: Sovremennaya logika: osnovaniya, predmet $i$ perspektivyi razvitiya [Contemporary logic: foundations, subject, and perspectives of development], ed. D. Zaitsev. Moscow: Forum, 2018, pp. 111-127. (In Russian) 